studies may be criticised because the number of patients was small and treatment lasted only four hours, ${ }^{9}$ there is a clear indication that postural manoeuvring has no dramatic effect in reducing the incidence of lumbar puncture headache. If, however, headache does develop and is severe it is generally agreed ${ }^{13}$ that the patient should lie flat until after the headache has disappeared.

Lumbar puncture remains an essential neurological tool, with unpleasant if short-lived sequelae in many patients. It is indicated in fewer conditions now since the advent of noninvasive procedures that provide more precise and specific diagnostic information.

Consultant Neurologist,

J M S Pearce

Hull Royal Infirmary, Hull HU3 2JZ

1 Quincke H. Die lumbarpunction des hydrocephalus. Berliner Klinische Wochenschrift $1891 ; 28: 929-65$.

${ }^{2}$ Merritt HH, Fremont-Smith F. The cerebrospinal fuid. Philadelphia: W B Saunders Co, 1937.

${ }^{3}$ Hayward Ri, O'Reilly GVA. Intracerebral haemorrhage: accuracy of computerised transverse axial scanning in predicting the underlying aetiology. Lancet 1976; i :1-4.

${ }^{4}$ Scotti G, Ethier R, Melancon D, Terbrugge K, Tchang S. Computed tomography in the evaluation of intracranial aneurysms and subarachnoid hemorrhage. Radiology 1977;123:85-90.

${ }^{5}$ Modesti LM, Binet EF. Value of computed tomography in the diagnosis and management of subarachnoid hemorrhage. Neurosurgery 1978;3: 151-6.

6 Findlay GFG. Computer-assisted (axial) tomography in the management of subarachnoid hemorrhage. Surg Neurol 1980;13:125-8.

${ }^{7}$ Aziz H, Pearce J, Miller E. Vasopressin in prevention of lumbar puncture headache. Br Med $\mathcal{f} 1968$;iv:677-8.

${ }^{8}$ Cowan JMA, Durward WF, Harrington H, Johnston JH, Donovan B. DDAVP in the prevention of headache after lumbar puncture. $\mathrm{Br} \mathrm{Med} \mathcal{F}$ $1980 ; 280: 224$

${ }^{9}$ Hilton-Jones D, Harrad RA, Gill MW, Warlow CP. Failure of postural manoeuvres to prevent lumbar puncture headache. 7 Neurol Neurosurg Psychiatry 1982;45:743-6.

${ }^{10}$ Easton JD. Headache after lumbar puncture. Lancet 1979 ;i :974-5.

11 Smith FR, Perkin GD, Rose FC. Posture and headache after lumbar puncture. Lancet $1980 ; \mathrm{i}: 1245$.

12 Carbaat PAT, Van Crevel H. Lumbar puncture headache: controlled study on the preventive effect of 24 hours' bed rest. Lancet 1981 ;ii: 1133-5.

${ }^{13}$ Clough C, Pearce JMS. Lumbar puncture. Br Med $\mathcal{f} 1980$;280:297-9.

\section{Unnecessary examinations?}

Medical schools are required by law to assess their students' competence, and the methods ${ }^{1}$ they use range from conventional essay questions and oral examinations, through multiple-choice questionnaires to continuous assessment, projects, or theses. All these may be backed by clinical examinations. Each method has advantages and drawbacks for examiners or candidates-and medical schools vary in the emphasis placed on each method-but clinical examinations are very widely used $\mathrm{d}^{2-5}$ because of the importance of assessing the fundamental skills of history taking and examination.

The use of patients in an examination creates problems. Conditions cannot be standardised for all candidates, ${ }^{6}$ examiners vary, ${ }^{78}$ and the same examiner may show inconsistency. ${ }^{7}$ Finding patients who are suitable "cases" may be difficult, as may transporting them (or making sure they turn up), feeding them, and allowing them home without excessive inconvenience. Ethical questions also arise when patients are asked to participate in procedures not directly concerned with their treatment; though such questions exist whenever patients are used for teaching, examinations may cause more stress and inconvenience- $\mathrm{a}$ fact that may be acknowledged by payment of a small fee to the patient or by giving him or her some priority on the waiting list.
The examiners themselves may recruit patients, but often $\underline{T}$ they delegate this duty to younger members of staff. In some 3 centres as many as 150 students are examined over two to three days, and the exercise may pose formidable administrative $c$ difficulties. The organiser (usually a lecturer or registrar) is under pressure to provide cases; patients may detect this and feel reluctant to add to his difficulties. When patients are $\mathbb{D}$ invited to help they have the option of refusing, but most co-operate-some enthusiastically, because they enjoy the attention; some dispassionately, because they recognise that examinations are a necessary part of training; and some, perhaps, reluctantly because they are unwilling to risk offending their doctors. No matter how tactful the request for co- $\bar{m}$ operation it carries medical authority, and some patients may $\mathbb{\widetilde { \Omega }}$ find it hard to refuse. Consent is usually given informallyand it would be a pity if forms requiring signature were introduced-but it should not be taken for granted, particularly in specialties such as psychiatry and paediatrics.

During the examination patients generally try to avoid irritating the examiners by making complaints. The smooth running of most clinical examinations is due partly to the good nature of the selected patients and partly to the skills of the doctors, nurses, and students in management; examiners are careful to protect the patients' interests and do their best to prevent tactless questioning or clumsy attempts at examination. Nevertheless, even a skilful examination may upset the patient in certain circumstances, and this problem arises particularly in gynaecology. Many medical schools still $\underset{v}{N}$ require students to demonstrate the ability to pass a vaginal $z$ speculum and perform bimanual pelvic examination under the stressful conditions of the final examination, despite the fact that all British medical schools operate some sort of assessment during the course in obstetrics and gynaecology. ${ }^{9}$ This specialty, perhaps more than others, is under criticism by consumer groups, who sooner or later are likely to question the practice of asking patients to undergo unnecessary vaginal examination. Gynaecologists would be wise to rely on the good will of patients only when there is no adequate alternative. Continuous assessment is already used in the specialty-for example, in conducting a normal delivery-and assessment during the course of the students' competence at pelvic examination would not be difficult to organise. The clinical examination could be based on history taking and on abdominal examination of obstetric patients. This small change in the format of student assessment is unlikely to lower academic standards: it would save some patients needless embarrassment - and would be better initiated by medical schools than by patients' associations.

${ }^{1}$ Charvat J, McGuire C, Parsons V. A review of the nature and uses of examinations in medical education. Geneva: World Health Organisation, $\mathcal{G}$ 1968. (Public Health Papers, No 36.)

2 Cuschieri A, Gleeson FA, Harden RM, Wood RAB. A new approach to a final examination in surgery: use of the objective structured clinical examination. Ann $R$ Coll Surg Engl 1979;61:400-5.

${ }^{3}$ Hubbard JP, Levit EJ, Schumacher CF, Schnabel TG. An objective N evaluation of clinical competence: new techniques used by the National Board of Medical Examiners. N Engl f Med 1965;272:1321-8.

4 Odling-Smee W, Love AHG, Irwin WG, Vallance-Owen J, Roy AD. An integrated final MB examination. Lancet $1982 ; \mathrm{i}: 1114-6$.

${ }^{5}$ Newble DI, Elmslie RG. A new approach to the final examinations in medicine and surgery. Lancet 1981 ;ii:517-8.

6 Stokes JF. The clinical examination. Dundee: Association for the Study of Medical Education, 1979. (Medical Education Booklet, No 2.)

${ }^{7}$ Royal College of Physicians of London. MRCP: 1977. Br Med f 1978; : 217-20.

8 Wilson GM, Lever R, Harden RMcG, Robertson JIS, MacRitchie J. Examination of clinical examiners. Lancet 1969;i:37-40.

${ }^{9}$ General Medical Council. Basic medical education in the British Isles. Vol 2. Reports on the teaching of the component disciplines/specialties of the medical course. London: Nuffield Provincial Hospitals Trust, 1977. , 